\title{
Information Systems in a Transdisciplinary Perspective: Leaping to a Larger Stage ${ }^{1}$
}

\author{
Jan Hendrik Kroeze \\ Bob Travica \\ Izak van Zyl
}

\begin{abstract}
The article argues that a transdisciplinary approach can advance the field of Information Systems (IS). By taking a transdisciplinary approach, researchers reach beyond the bounds of their disciplinary ontology and epistemology in order to address complex phenomena. Such a high level of synthesis is not possible with interdisciplinary and multidisciplinary approaches. While these approaches have been deployed in the IS field, transdisciplinarity is still lacking. The article reviews the literature that indicates the relationship between transdisciplinarity and complexity, and posits that the former is a response to the latter. Following a conceptual research approach, it is demonstrated that mainstream IS research is interdisciplinary and multidisciplinary rather than transdisciplinary. Finally, it is argued that the IS field is a promising candidate for ascending up the transdisciplinary path that, in turn, can improve its development prospects.
\end{abstract}

Keywords: Complexity, transdisciplinarity, disciplinarity, multidisciplinarity, interdisciplinarity, Information Systems

${ }^{1}$ This article is a revised and extended version of an earlier conference paper by Jan H. Kroeze and Izak Van Zyl, 'Transdisciplinarity in Information Systems: Extended Reflections' (2014). Twentieth Americas Conference on Information Systems Proceedings, Savannah, Georgia, 7-9 August 2014, 110. https://aisel.aisnet.org/amcis2014/ISPhilosophy/GeneralPresentations/1/ 


\section{Introduction}

The discussion in this article is based on the presuppositions that the contemporary, socio-technical world is complex and requires a transdisciplinary approach to research (Porto de Albuquerque \& Simon 2007). We conceptualise complexity in terms of a larger differentiation of a system and a larger multiplication of relationships between the system parts. We posit that the transdisciplinary approach is based on open ontology and epistemology, allowing for a very high level of knowledge synthesis. Next, we presume that complexity in phenomena requires transdisciplinarity in research. Finally, we suggest that transdisciplinarity is lacking in the Information Systems (IS) field, while its open character and initial interest are amenable to a transdisciplinary transition. Since the IS discipline plays an important, conducive role in linking divergent disciplines and facilitating boundary spanning across research fields (Liu et al. 2017), transdisciplinarity is a suitable approach for the discipline to solve complex problems not only in the field itself but also in the outside world. The purpose of the article is to stimulate the IS discourse into thinking beyond interdisciplinarity. Classical philosophy is transdisciplinary and so are various attempts in the systems realm (complex systems, complexity theory) (Carayannis, Campbell \& Rehman 2016). Since transdisciplinarity is still rare in the IS field, the article aims to clarify how transdisciplinarity differs from interdisciplinarity and to suggest theoretical and practical guidelines for its evolution.

All domains of the modern world are characterised by some form of complexity. Complexity is typically considered as a stronger and deeper differentiation within complex systems, with a substantial multiplication of relationships between the differentiated parts. Complex systems emerge in a non-linear, non-deterministic and dynamic manner and are characterised by random probability patterns (Kirshbaum 2002; Lucas 2000; Raymond, Horsfall \& Lee 1997). For a social researcher, the social world manifests one domain of complexity. Techno-stress, for example, is regarded as a multidimensional and non-linear phenomenon that should be addressed by a combination of theories and approaches (Issa \& Bahli 2018). The globalised economy escapes control and prediction (Castells 2012), which becomes obvious with every new prolonged recession or wild fluctuation in markets. Complex political systems are characterised by dynamic networks, which engender emerging, startling policy failures and alliance shifts (Root 2013). Health, education, infrastructure, urban and other social aspects constitute 
complex system domains in their own right. Organisations are immersed in competitive, volatile environments that challenge organisational survival (Teece, Pisano \& Shuen 1997; Teece 2007). Technology built into organisations and society is yet another crucial domain of contemporary complexity (Gill 2013; Travica 2015; Weick 1990). The non-linearity of the contemporary, Internet-based world implies that small changes in the components of this complex network can cause disruptive changes in the whole system (Onik, Fielt \& Gable 2017).

Complexity shapes research problems that challenge researchers in this time. These problems are not domain-exclusive but rather span various domains: economy to politics; various social aspects to economy and politics; organisation to all these as they constitute organisational environments; and so on. While being a means of resolving environmental complexity, organisational technology exhibits complexity in design, its workings, and in interfacing with users' cognition (Travica 2015). According to the cybernetic law of requisite variety, a stable system is one that has a repertory of responses that matches the range of disturbances coming from its environment (Ashby 1991; Jackson 2015). It follows from this law that effective human-technology coupling has to correlate with environmental complexity.

The same cybernetic law compels seeking research approaches capable of coping with complexity. More than forty years ago, scholars from different disciplines realised that isolated disciplinary approaches ceased to be capable of addressing contemporary problems in theory and practice effectively (Piaget 1972). The visionary scholars felt as the metaphorical wise thinkers, each touching a different part of an elephant while trying to explain the elephant in its entirety. Tensions between complexity of phenomena and particularistic inquiry had burst out. Then, a new wave of interest in transdisciplinarity emerged in the 1990s, strengthening the foundations and setting clear research routes (Gibbons et al. 1994; Nicolescu 1994). The foundational work included a differentiation between transdisciplinarity, interdisciplinarity and multidisciplinarity. All these approaches deviated from the disciplinary (intradisciplinary) approach, albeit in differing manners. Extensive digitisation during the past few decades created an open but networked society that could be studied using cybernetics; only a transdisciplinary approach finding new syntheses of knowledge can unlock future opportunities of the digital world (Jackson 2015).

More recently, interest in transdisciplinarity has surfaced in the IS 
field (Cohen 1999; Gill \& Cohen 2009; Liu et al., 2017; Nguyen et al. 2015; Porto de Albuquerque \& Simon 2007; Wahoff, Porto de Albuquerque \& Rolf 2012). Consequently, the relationship between IS research and transdisciplinarity has become a research problem in its own right. Its rationale starts with the obvious premise that the IS field has always been open to inputs from various disciplines, rather than having an intradisciplinary focus. But is the field transdisciplinary or something else? We will argue that it is not there yet. Rather, it is typically interdisciplinary and at times multidisciplinary. However, interest in transdisciplinarity has been expressed programmatically and conceptually. Liu et al. (2017), for example, developed bibliometric algorithms that visualise how IS has become a key player in the facilitation of transdisciplinarity in knowledge creation. We argue that the IS field itself can ascend to transdisciplinarity. The transdisciplinarity capability of the IS field has implications for its prospects addressed in the ongoing soul-searching process (Desouza et al. 2006; Hirschheim \& Klein 2012; Looney et al. 2014; Straub \& Ang 2011).

\section{Methodology}

The article follows a conceptual research approach. Conceptual research is philosophical in nature and is used to develop new theoretical or abstract ideas and to reinterpret existing concepts (Kothari 2004; Yadav 2010). It is nonempirical and complements qualitative and quantitative approaches as one of three pervasive research methods in Information Systems (Mora et al. 2008). Mathematical study is also non-empirical and often regarded as formal (rationalist) science (Markie 2017). Both mathematical and conceptual research follow a rational approach to create systematic knowledge that should be verifiable or falsifiable by showing the 'logical consistency' and 'rational justification' of the scientific arguments to be feasible or inappropriate (Kroeze 2013:43).

Conceptual research, therefore, can be regarded as form of rationalism or, actually, transcendental idealism, originally developed by Immanuel Kant (Kant 1977). Kant reconciled empiricism and rationalism (Kroeze 2013) making it clear that science needs both reason and experience in its endeavours to explain the world (Buckingham et al. 2018; Magee 1999).

Science, in other words, consisted entirely of immediate observation 
plus logic, and these were two processes which, if carefully and properly executed, yielded the highest level of certainty that there could be (Magee 1999:142).

Kant's Copernican revolution regarding the nature of understanding added another aspect to his epistemology. It reversed the intuitive concept that humans get knowledge by more or less passively observing things in the world. Creating knowledge became a deliberate human action that is enabled by, but also limited to, the capacities of the human senses and brain, thus imposing certain 'categories' (such as time, space and cause) on the concrete world (Magee 1999:146). Knowledge is not a mere representation of the world but an interpretation of it and therefore a human construct. Although a concrete world exists out there, we humans can never be sure that we can experience and know all of it (Kant 1977; Kroeze 2005).

Therefore, it is not only the social world that is a human construct, but also our understanding of the physical world, on which we impress the socalled a priori categories of the human mind during our processes of sensemaking.

The sensible world, or the world of appearances, is constructed by the human mind from a combination of sensory matter that we receive passively and a priori forms that are supplied by our cognitive faculties (Rohlf 2018).

Computer algorithms and computing theories are part and parcel of the artificial world of constructs and relationships created by scientists:

When authors set out to develop a theory, they create an artificial world that comprises constructs and their relationships, which they posit will hold within the boundaries of the theory. This artificial world is akin to the computer algorithms I refer to above. Its constitutive elements are the constructs, the assumptions, the boundary, and the relationships among the constructs (Rivard 2014:xi).

The conceptualisations underlying software models and simulations are based on human perceptions and abstractions of reality (Tolk et al. 2013). Kant's 
emphasis on human reason as an essential component of scientific thinking based on his 'constructivist view of experience' (Rohlf 2018) - makes it undeniable that conceptual research is as important as quantitative and qualitative empirical research.

Some IS journals, like the Journal of the Association for Information Systems, have special sections dedicated to well-argued conceptual work 'that address critical issues that shape the IS research tradition' (Hirschheim 2008:433). Papers that deal with perspectives on IS research are supposed to stimulate debate in order to overcome compartmentalisation of subdisciplinary groups. Therefore, they are also called opinion or debate papers. MIS Quarterly also has a strong tradition of conceptual or theoretical research (Rivard 2014; Webster \& Watson 2002; Zmud 1998). The journal has three dedicated sections for methodology, theory and review, and opinion articles (https://misq.org/categories). An example of a debate and perspective article in the Journal of Information Technology, is Davison and Martinsons (2016), who make a case for more contextualised research in Information Systems that could open the door for the integration of indigenous knowledge systems and research approaches in the field.

Conceptual research uses critical reasoning to debate issues (MacInnis $2011 ; 2016 / 2017)$. It is argumentative and subjective and, from an empiricist viewpoint, sometimes regarded as less scientific (Markie 2017). However, according to Hirschheim (2008:433) all research papers are based on opinions (hypotheses/theoretical statements) and, therefore, 'opinion papers' are not less scientific per se:

One cannot categorically state that papers based on opinions are unscholarly. It is what these opinions are based on, how they are supported, and how they are formulated that makes them more or less believable; and ultimately, whether we ascribe to them the label 'contribution to knowledge' that is important. Indeed, some of the most influential and widely cited papers in the field are of this type.

Since the word 'opinion' may be interpreted in everyday language as a speculative point of view, we choose to rather use the word 'conceptual' to describe this research. The purpose of a conceptual article is to develop discourse, to build theory or to develop methodology. Conceptual research can be regarded as rigorous if its logic is consistent and if it can be rationally 
justified. Conceptual research is important in science to challenge normal scientific presuppositions and approaches by proposing new theoretical vistas that may be tested empirically in follow-up work. In IS, conceptual research outputs are viewed as important to ensure integration of diverse approaches and to debate the course of future IS research. The importance of conceptual articles is also recognised in other disciplines such as Marketing (Yadav 2010).

Each discipline must collectively negotiate a balance between conceptual and empirical contributions to maintain a vibrant environment for knowledge development (Yadav 2010:5).

While 'normal science' usually does not lead to ground-breaking new insights, conceptual reflection is important to question existing paradigms (Kuhn 1970:35, 88).

In the rest of the article, foundations and development trajectories of transdisciplinarity will be discussed based on a broader literature. Then follows a discussion on the IS literature's reaching beyond the disciplinary approach, which still falls short of empirical transdisciplinary research. This approach is similar to a taxonomy development method proposed by Nickerson, Varshney and Muntermann (2013). Based on an extensive literature review (Nickerson, Muntermann \& Varshney 2010), their method follows an iterative approach consisting of various conceptual-to-empirical and empirical-to-conceptual cycles. Our article is also based on a wide-ranging literature review that first theorises deductively about the concept of transdisciplinarity and then examines 'objects' (i.e. multi-, inter-, and transdisciplinary research outputs in IS) to confirm the theoretical concept. This is similar to Nickerson, Varshney and Muntermann's (2013) conceptualto-empirical phase. Although we do not have a separate empirical-toconceptual (inductive) phase, we conclude the paper with an argument on the possibilities of transdisciplinarity in IS research that could address this gap in follow-up work. A comparable methodology was followed by Diallo (2010) who used various cycles of critical literature review and deductive reasoning to develop and evaluate a formal data model that could facilitate the interoperability of alternative software systems that reflect different interpretations of the real world.

This article makes a meta-theoretical contribution towards theory buil- 
ding in Information Systems by extending and refining our current understanding of transdisciplinarity and its relevance for the field. According to Liu et al. (2017), there is a lack of conceptual and methodological research regarding transdisciplinary theory. 'Contribution to a theory is determined by whether a manuscript extends, empirically tests, refines, or critiques the theory' (Larsen et al. 2019: 891). The clarification of intra-, multi-, inter- and transdisciplinary research in IS may be regarded as one small step to advance network and complexity theory towards a coherent framework that could be used to address uncertain and complex organisational and knowledge issues (cf. Morçöl \& Wachhaus 2009). The article, therefore, addresses some of the 'grand challenges' for IS research as identified by Becker et al. (2015), i.e. to reflect on its own theoretical foundations in order to help solve important societal issues.

\section{Roots and Trajectories of Transdisciplinarity}

The advent of transdisciplinarity resulted from a reaction to the rigid division between sciences and specialisations inherent to the disciplinary approach. Today's academia rests on disciplinary divisions. Their history is long in Western civilisation, and it can be traced back to institutionalised schooling in ancient Greece. Modern lexicons readily cite two definitions of 'discipline' a branch of knowledge, and behavioural obedience to rules (Oxford Dictionaries Online 2016; Merriam Webster Online Dictionary 2016). As a branch of knowledge, a discipline has a defined subject of study. A disciplinary inquiry thus enlightens and deepens understanding of the subject of study. These effects seem to contradict the obedience-focused definition. But in fact, the definitions are congruent.

A disciplinary approach indeed compels to complying with the rules of legitimate subjects of study and acceptable research methods. While deepening the mind on the one hand, a discipline delineates and constrains it, on the other. A price to pay for specialist knowledge is a lack of holistic thinking and knowledge. This is sometimes labelled as the incapability of thinking 'out of the box'. The metaphor of incomprehensible complexity eluding blind students of the elephant has many current renditions, such as the human body, climate, society, market, organisation and the Internet. These phenomena have provoked renewed calls for freeing the mind from disciplinary constraints via a transdisciplinary approach. 
Modern roots of transdisciplinarity date back to the 1970s. Developmental psychologist Jean Piaget and a group of like-minded scholars from different disciplines raised a concern regarding limitations of contemporary sciences. Piaget (1972:138) referred to the term as,

a higher stage succeeding the stage of interdisciplinary relationships ... which would not only cover interactions or reciprocities between specialised research projects, but would place these relationships within a total system without any firm boundaries between disciplines.

Research that reshapes traditional borders of disciplines by accommodating novel scholarly ideas facilitates transdisciplinarity since it opens up new fields for research (cf. Onozuka, Yamazaki \& Kokuryo 2016). While the agreement about the synthesis and integration of knowledge for the sake of improving research and education was commonly shared among the forefathers of transdisciplinarity, some of them also stressed the goals of innovation, improvement of human conditions, and social relevance of research and education (Bernstein 2015). Transdisciplinarity continued owing to thinkers who were bold enough to challenge the mainstream disciplinarity. The 1994 Charter of Transdisciplinarity adopted at the First World Congress of Transdisciplinarity states:

Rigor, opening and tolerance are the fundamental characteristics of the transdisciplinary attitude and vision. Rigor in argument, taking into account of all existing data, is the best defence against possible distortions. Opening involves an acceptance of the unknown, the unexpected and the unpredictable. Tolerance implies acknowledging the right to ideas and truths opposed to our own (Nicolescu 1994).

In the same spirit, the Charter pledges for openness and tolerance in understanding the human being, reality, logic, objectivity, time, history, myths, religions and culture. Article 5 of the Charter positions transdisciplinarity as an expansive approach that overarches disciplines as disparate as science and religion: 
The transdisciplinary vision is resolutely open insofar as it goes beyond the field of the exact sciences and demands their dialogue and their reconciliation with the humanities and the social sciences as well as with art, literature, poetry and spiritual experience (Nicolescu 1994).

The complex phenomena inviting a transdisciplinary approach are sometimes called wicked problems. Such problems resist simple solutions and require a broad-based, persistent research effort. Wicked problems compel the use of multiple prongs of research to solve puzzles of sustainability, climate change, social justice, crime, education, health, sanitation, community development and housing (Lawrence 2010). Founders of transdisciplinarity for the most part agree about differences between approaches that are alternatives to disciplinarity. In contrast to a higher-level synthesis of multiple disciplines into a trans-discipline, multidisciplinarity normally gathers contributions from different disciplines without actual synthesis, while interdisciplinarity integrates knowledge from several disciplines (Bernstein 2015). Although synthesis is regarded as typical of systems thinking (Demetis \& Lee 2016), systems theory often stops short of deep integration: there is a reciprocity of ideas without changing the essence of any of the involved disciplines (Alter 2015:9).

The ideas about transdisciplinarity and alternative research approaches are represented in Figure 1. The suggested properties of intellectual openness and tolerance point to the realm of ontology. It can be represented as an axis with a closed and open end. The line-up of the alternative approaches along it is: disciplinarity, multidisciplinarity, interdisciplinarity and transdisciplinarity (Figure 1). Disciplinarity tends toward a closed philosophy. Multidisciplinarity opens up ontology but only in a mechanical manner without true integration. Interdisciplinarity achieves such integration. The open end of the continuum signifies transdisciplinarity as an open philosophy inclining toward ontological synthesis. Epistemological relationships between these approaches are equivalent and can be mapped onto the vertical axis with a closed and open end. Since transdisciplinarity allows environmental factors as input in the knowledge creation process, it may be regarded as an open system with an open ontology that necessitates a range of open, epistemological approaches that could either lead to equifinality (convergent outcomes) or multifinality (divergent outcomes) (Demetis \& Lee 2016). 


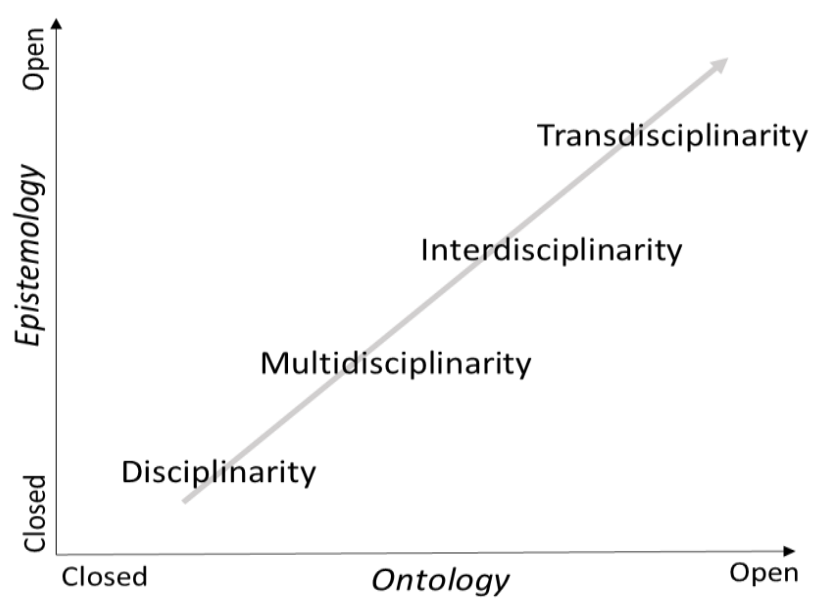

Figure 1. Relationships between research-approach options based on ontology and epistemology

A transdisciplinary trajectory that has focused on complex societal problems completed the conceptual foundations of transdisciplinarity (Gibbons et al. 1994). Its proponents have advanced Mode 2 knowledge production, which involves cross-disciplinary collaboration on real-world problems, with experts from government, industry and academia. This line of transdisciplinary research should materialise via projects focused on practical problem solving, by uniting sciences, technology and the humanities (Bernstein 2015).

In accordance with this approach, Nowotny (2004) argues that the practical focus of Mode 2 knowledge necessitates a change even in the criteria for assessing 'good science.' Such science has to be 'societal valueintegrated'. Mode 2 knowledge creation refers to transdisciplinary research and non-linear (disruptive) innovation, while Mode 1 knowledge creation can be regarded as a synonym for intradisciplinary research linked to linear innovation (Carayannis, Campbell \& Rehman 2016). Transdisciplinary research needs to follow this path to be able to address

the management of complexity in a public space, which is neither state, nor market, neither public, nor private, but all of this in different configurations (Nowotny 2004:6). 
Adding the criterion of social significance to the property of complexity results in the graphic shown in Figure 2.

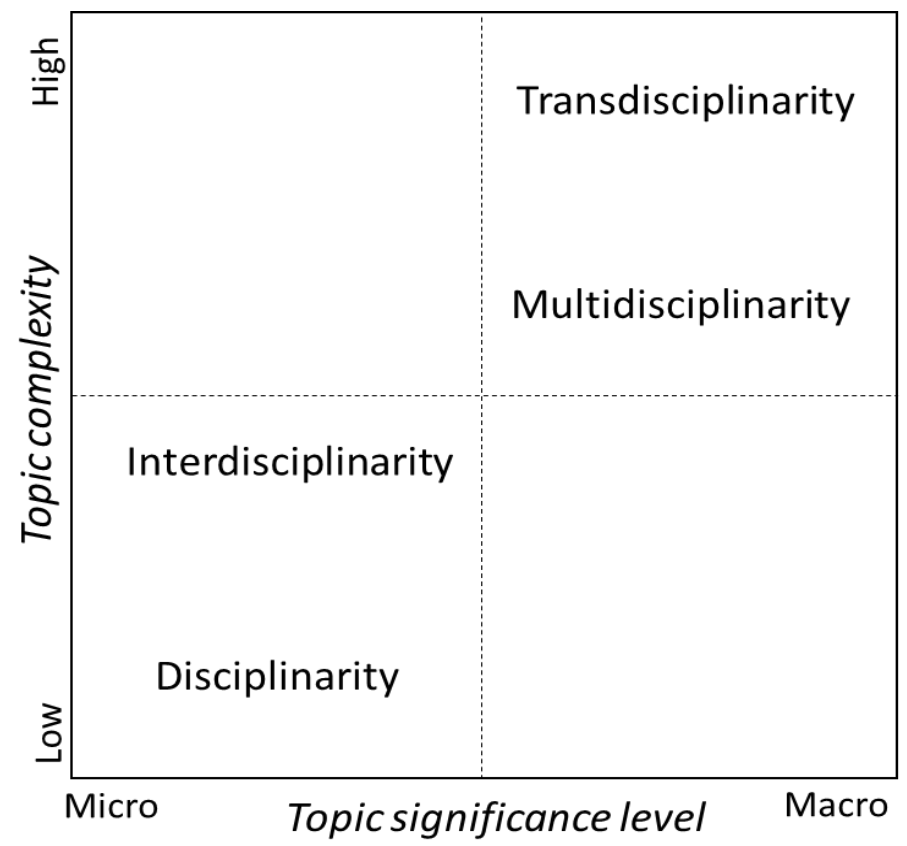

\section{Figure 2. Research-approach options as functions of complexity and significance}

Both disciplinarity and interdisciplinarity address topics with a micro level of significance and of lower complexity. For example, these approaches may arise from the intention to assist organisational management of big data or a community's improvement with the help of social media. In contrast, transdisciplinarity and multidisciplinarity are motivated by grand, complex problems infused with a macro societal significance. For example, a trigger for these approaches may be an urge to solve a multi-facetted, deeply-seated social problem with information and communication technology (ICT) as part of a desired solution. ICT needs to be approached from a complexity perspective; that is, at the intersection of the material, social, personal and intellectual worlds (Travica 2015). Material functionality of technology embeds a substantial social heritage, a part of common human intellect and a designer's 
professional knowledge. When used, technology is appropriated/modified by individuals and social organisations (groups, firms, communities) (Bemgal 2018). This complex ontology of technology corresponds to the macro societal significance of research problems.

Since transdisciplinarity offers competent answers to complexity, advancing theory of complex systems has merits for the development of the transdisciplinarity approach in research. Disentangling complexity from complicatedness is one distinction that is important for this development. Complicated systems may be understood in terms of their individual components, while this may not be the case for complex systems. It is because parts of a complex system interact in such a way that the system properties and behaviours are emergent rather than given. The emergent character of a complex system is a consequence of the system irreducibility principle, according to which a complex whole is not explicable in terms of its parts. An example of emergence is the wetness of water: this property emerges from interaction of water's constitutive molecules rather than from their individual wetness (Holland 2014). By the same analogy, the Internet as a socio-technical phenomenon cannot be understood deeply by studying merely its technical and social constituents but rather from studying dynamic outcomes of their interaction. The system irreducibility principle runs against the wisdom of the classical analytical approach that taking a whole apart ascertains a deep understanding. It challenges expectations that particle physics can explain behaviour of higher forms of matter, or that associations between humans and non-humans (e.g., technology) can explain systems arising from their interaction.

The property of emergence applies to transdisciplinarity as theories, data and methodological approaches from different domains are synthesised into something new that, in turn, cannot be reduced into the contributing disciplinary components (Leavy 2011). Because of this, transdisciplinary research practice is non-linear and emergent, as unforeseen dynamics and new insights materialise. A transdisciplinarian evaluates problems from multiple perspectives to discover 'hidden connections between different disciplines' (Madni 2007:3). A transdisciplinarian is an imaginative and lateral thinker, considering multiple solutions and factors to complex problems (Clark \& Button 2011).

A transdisciplinarian must break free of 'reductionist and mechanistic assumptions about the ways things are related, as how systems operate, and the expectation science delivers a single "best" solution or final answers" 
(Klein 2014: 72). This sort of scholar has to be able to absorb the pain resulting from abandoning one's intellectual comfort zone of a learned discipline, and to engage in new modes of thinking and acting (Augsburg 2014). Transdisciplinarians help to produce a common agenda where 'transdisciplinary unity' replaces the simple grouping of individual disciplinary components (Mittelstrass 2011).

While a multi-theory/multi-method orientation characterises both interdisciplinarity and multidisciplinarity, the latter approach stays more on the surface. As mentioned above (refer to Figure 1), the key shortcoming of multidisciplinary research projects is that they tend to 'mechanistically pool the expertise of participant disciplines' (Kyriakidou \& Ventners 2007:840). Consequently, collaborators in a multidisciplinary project do not exhibit a shared understanding, and communication breakdowns are possible. The initial ontological, epistemological and methodological differences tend to remain intact. Full disciplinary integration is limited to the mechanical grouping of research data, and different perspectives are merely compared rather than changed or integrated (Choi \& Pak 2006).

Both the transdisciplinary and interdisciplinary approach share the idea of integrating concepts and methods across disciplines in order to explore and solve problems that cannot be dealt with in a single discipline. In a postmodernist vocabulary, both approaches deconstruct disciplinary premises with the goal of overcoming disciplinary self-boundedness that is institutionalised in research specialisations, academic journals' agendas and university programs (Hovorka 2010). They can either aggregate or 'crystallise' knowledge from various fields into an integrated, innovative new construct, or they can disseminate or 'liquidise' knowledge from one field to other fields, while intra-disciplinary and multi-disciplinary approaches focus more on the validation and reinforcing of existing knowledge (Liu et al. 2017).

Applying these ideas to topic construction across the differing research approaches, we arrive at a mapping depicted in Figure 3. In the transdisciplinary approach, the topic is part of a common research agenda produced by research partners with different scientific backgrounds. Their agreement shapes a research topic. In contrast, in the multidisciplinary approach, the topic can be phrased by a client, while researchers look at it through their own disciplinary window. The interdisciplinary approach constructs the research topic at the intersection of contributing disciplines. Standing in opposition to all three, the disciplinary approach constructs topics exclusively from its own 
body of knowledge.
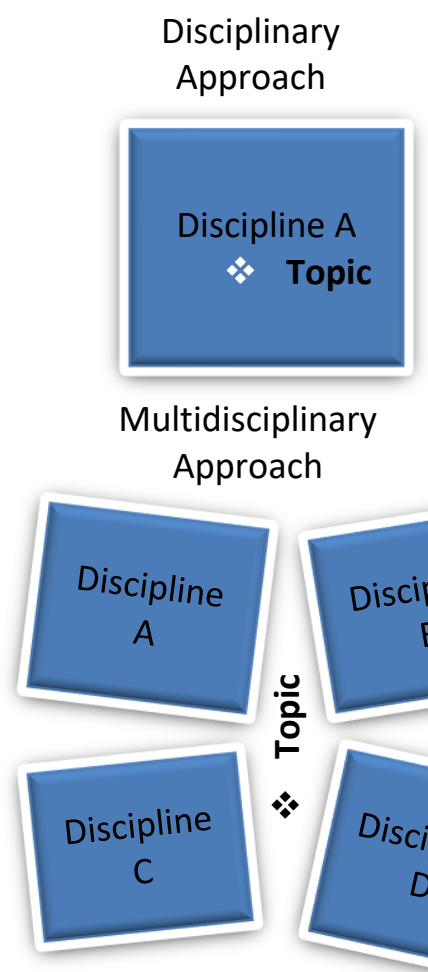

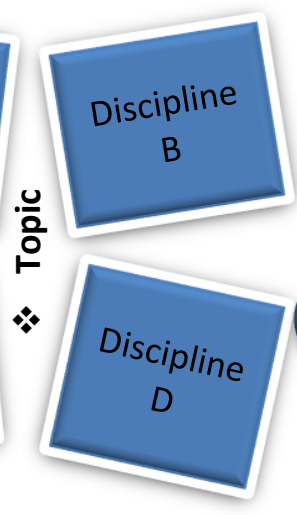

Interdisciplinary

Approach

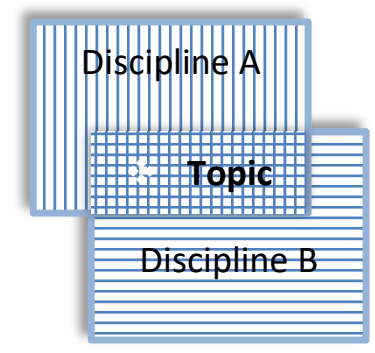

Transdisciplinary

Approach

\section{Figure 3. Topic construction in transdisciplinarity and alternative}

\section{approaches}

Table 1 summarises characteristics of beyond-disciplinary research approaches and contrasts transdisciplinarity to the options. A semi-open view on ontology and epistemology implies that researchers are sensitive for a diversity of world-views and knowledge theories, although they themselves still work within their traditional paradigms. An open view on ontology and epistemology implies that the researcher himself of herself uses different knowledge theories that suit diverse world-views. The idea of an open ontology is based on Popper's (1978) demarcation of three worlds: the material world, the world of experience and the world of human thought constructs (the intellectual world) 
of which algorithms and information systems form part and parcel (Rivard 2014; Tolk et al. 2013). IS has a wide and open field of research dealing with aspects of computer and human interaction in the widest sense of the word, and therefore IS research also needs a wide range of epistemologies and research approaches that can be mapped on Popper's three worlds or Travica's (2015) four worlds (adding the social world to Popper's three realities).

What is clear is that IS is unique in the sense that it is neither exclusively computer science [intellectual], nor is it exclusively organizational science [social]; it is neither exclusively the life sciences (psychology, sociology or political science) [experiential] nor is it exclusively engineering [material and intellectual] (Hassan 2011:472).

Topic complexity refers to the level of 'wickedness' of a problem that has to be solved using a variety of epistemological approaches (Travica 2015). Theoretical problems have a lower level, and practical problems have a higher level of complexity. Significance level refers to the possible impact that a related research initiative will have. Endeavours that try to solve practical problems have more impact (macro) than those focusing on theoretical problems (micro). Collaborative nature describes the extent of diverse disciplines that are involved. While an interdisciplinarian usually is a specialist on a small number of disciplines, multi- and transdisciplinary research requires collaboration across a variety of fields. The knowledge goal of the various approaches can be differentiated with reference to the understanding vs. the solution of problems. With reference to the knowledge character, multi-disciplinarity merely combines constructs from various disciplines (for example, a compilation of insights from Computer Science, Information Systems and Software Engineering on the web), interdisciplinarity integrates such constructs (for example, a theory that applies linguistic concepts in systems analysis and design), and transdisciplinarity synthesises knowledge (for example, a new discipline such as Data Science that emerges by accommodating inputs from various disciplines in a new unit) (National Science Foundation 2019; cf. Ghani 2018). While multidisciplinarity does not change the contributing disciplines at all, both inter- and transdisciplinarity enriches them by challenging and expanding their boundaries that may even lead to paradigm shifts. 
Information Systems in a Transdisciplinary Perspective

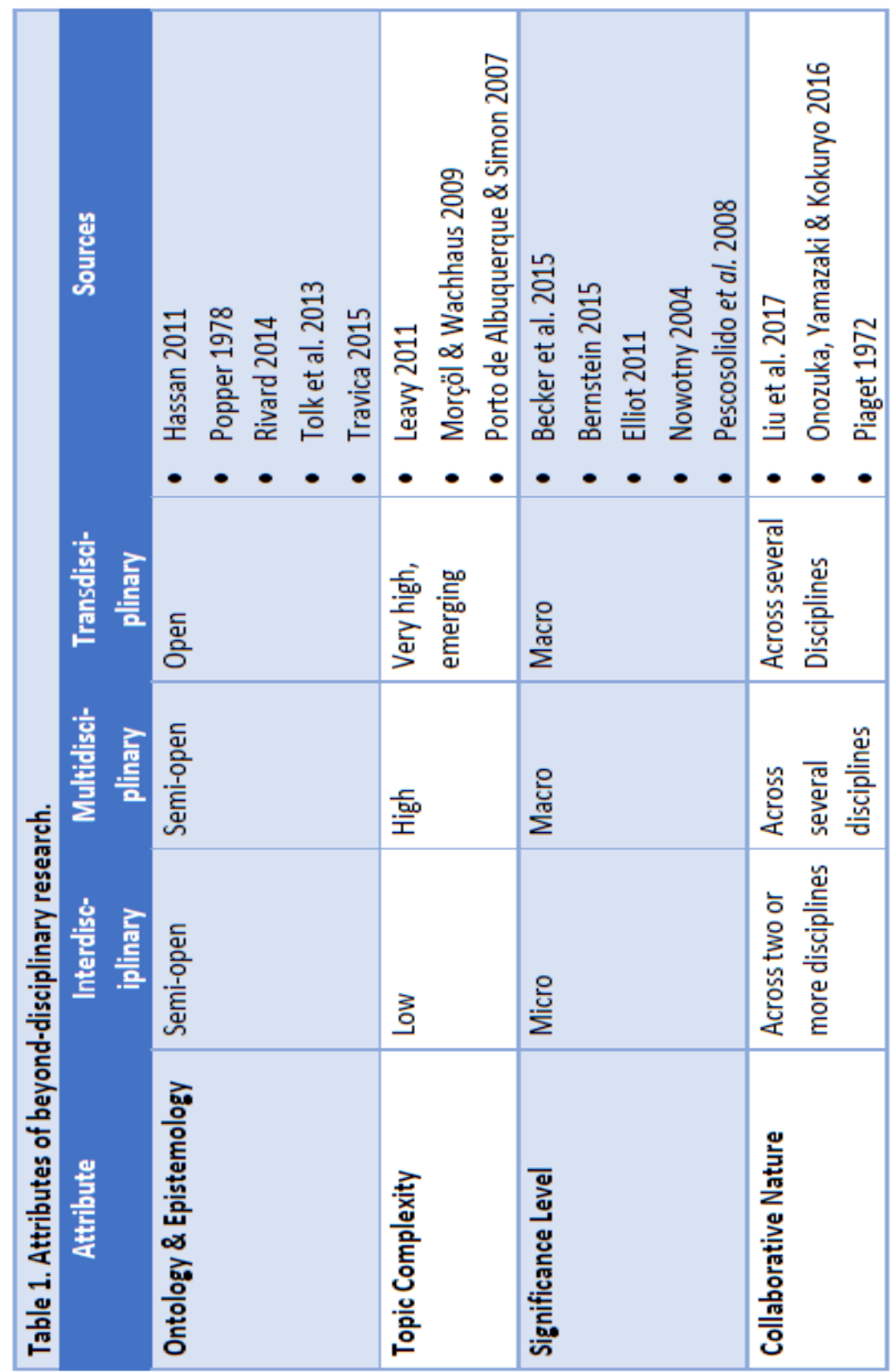


Jan Hendrik Kroeze, Bob Travica \& Izak van Zyl

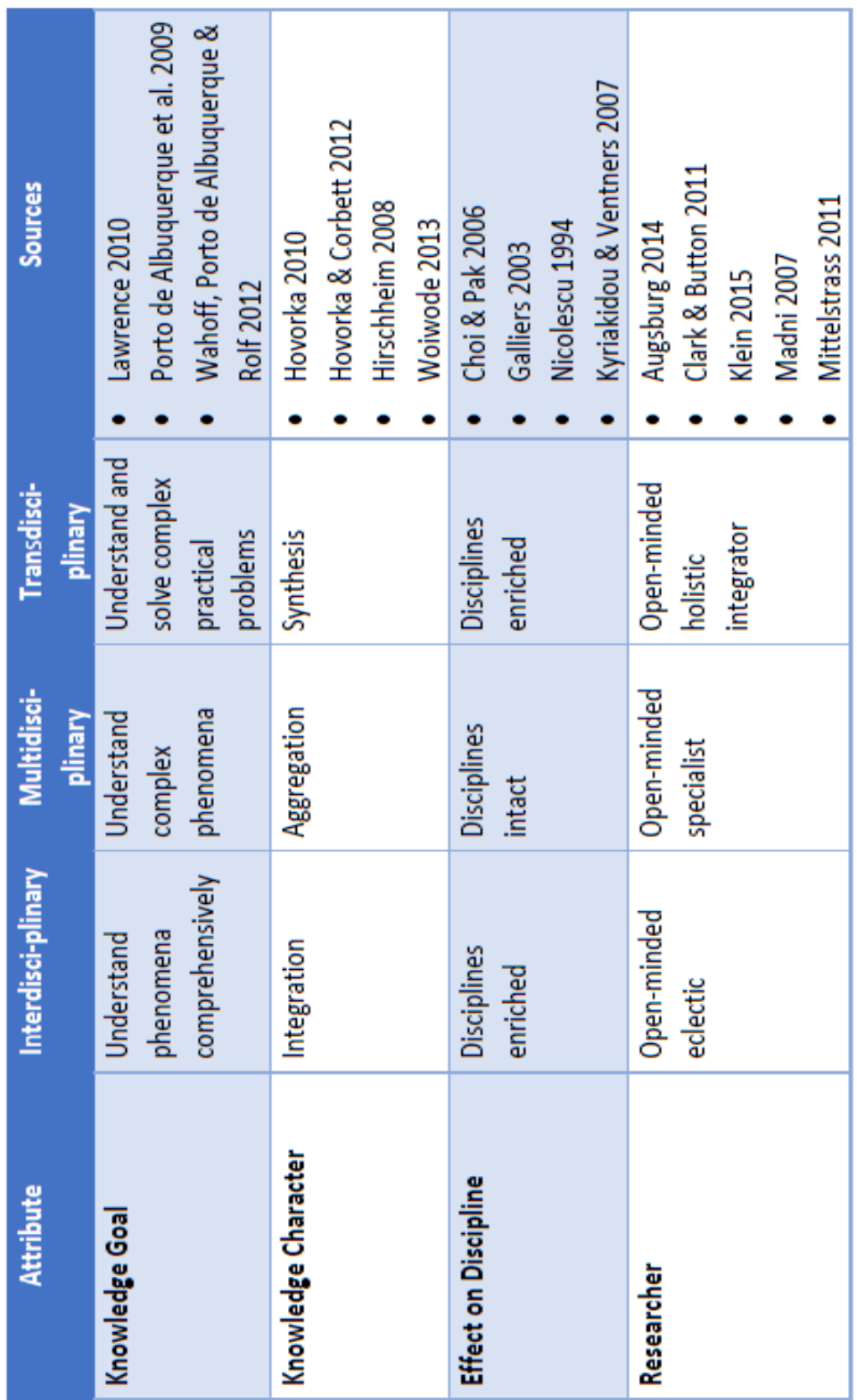


Open-mindedness characterises a researcher's broader perspective as an inclination towards boundary-spanning. The attempt to overcome traditional disciplinary restrictions can be eclectic (a researcher has the skills to derive and integrate ideas from various disciplines on a theoretical level), specialist (researchers' endeavours to allow complementing inputs of researchers from various disciplines) or holistic (a researcher's ability to synthesise ideas from various disciplines into new constructs to solve wicked practical problems).

The fourth column in Table 1 synthesises the various ideas regarding transdisciplinarity that have been gleaned from related literature; the fifth column lists some of the prominent sources. Transdisciplinarity deploys open ontology and epistemology for dealing with highly complex, emerging practical problems of a macro-societal significance. Such research solves practical problems and aims at high synthesis of knowledge. A transdisciplinarian is an open-minded and holistic thinker who brings disciplinary knowledge into a new synthesis by overcoming its methodological and theoretical bounds. This synthesis of ideas is one of the main contributions of this conceptual article. These characteristics form a blueprint of transdisciplinarity, which can be used for assessing transdisciplinary ambitions of research streams.

In summary, a call for a transdisciplinary research approach was a reaction to the rigid division between sciences and specialisations inherent to the disciplinary approach. Transdisciplinarity has some similarities with other beyond-disciplinary approaches - while scaling up synthetic capabilities regarding ontology and epistemology and focusing on complex, wicked practical problems.

\section{Reaching beyond Disciplinarity in the Information Systems Field}

The IS field has always been open to inputs from various disciplines. IS scholars tend to view what they do as a 'field' rather than a 'discipline', and some authors overtly plead against IS becoming a discipline (Hassan 2011). Invoking the vocabulary discussed above, we posit that the sheer foundations of the IS field lean toward multidisciplinarity and interdisciplinarity because they merge computer science subjects and social and behavioural disciplines. 
Some authors characterise the IS field as interdisciplinary (Dreschler 2013; Porto de Albuquerque \& Simon 2007). Mini-fields of IS research are typically defined by hybrids involving IS concepts/frameworks on one side and established disciplines on the other (e.g., individual psychology, group theory, economics, management theory and organisation theory). A more recent interest in hermeneutics follows suit. Developed in humanities disciplines, hermeneutics has been used for interpreting ancient texts. Karppinen et al. (2014) studied reasons for the non-adoption of a medical behaviour change support system. The authors reverted to hermeneutics to come to grips with the unexpected reasons that participants indicated for not adopting the system, even though they had positive perceptions about it.

Interdisciplinary frameworks have surfaced in the IS field. For example, the framework Informing View of Organisation (Travica 2014) crosses IS theory and organisation theory. The framework intersects the main views of organisation (structural, cultural, process, political) with core concepts in the IS field (information system, data, knowledge, information, ICT). The result of integration is new concepts (homo informaticus, structure of informing, culture of informing, and the like). These have guided case research and produced novel insights into issues surrounding the IS life cycle.

Multidisciplinarity, another beyond-disciplinary approach, also has applications in the IS field. Examples are health informatics and geographical IS. In addition, social media research can bring together IS research and marketing, media study, social psychology, communication and potentially others. Recall that multidisciplinarity is superior to interdisciplinarity in addressing problems at a higher societal level, while being inferior regarding ontological and epistemological integration. Still, the fine lines separating multidisciplinarity from interdisciplinarity need to be tested on each single study rather than considering IS studies a priori to be in either rubric.

Transdisciplinarity has also received attention of IS scholars. However, its treatment is programmatic or conceptual rather than empirical. Resembling concerns of the transdisciplinarity founders discussed above, IS scholars appeal for embracing transdisciplinarity in order to expand theoretical pluralism and avoid self-defeating reductionist agendas (Galliers 2003). The ultimate reason is in coping with what is viewed as multidimensional problems that are challenging IS researchers increasingly (Porto de Albuquerque, Simon, Wahoff \& Rolf 2009). This is also consistent with the foundations of transdisciplinarity. 
An example of conceptual transdisciplinarity is the framework called Mikropolis intended for studying the development and use of IS (specifically) and ICT (generally) at a societal level (Wahoff, Porto de Albuquerque \& Rolf 2012). The framework is consistent with the idea discussed above that transdisciplinary research has a broad, societal scope and a focus on practical problems. The authors argue that the boundaries of real-world and complex problems do not always adhere to the limits set by scientific and academic disciplines. Furthermore, Nguyen et al. (2015) postulated that researchers could address the generation gap by involving young and elderly people as teams in social computer games. Such an approach would improve computer literacy of the elderly, communication between age groups and mutual understanding. The transdisciplinary character of this endeavour would be in integrating concepts from gerontology, psychology, communication and computing in order to solve practical problems (the loneliness of a growing elderly population and unfavourable perceptions between age groups). The subdiscipline of Information and Communication Technology for Development (ICT4D) addresses the societal aspect of IS directly and will, therefore, be examined below as one of the most promising areas for transdisciplinarity in IS.

Informing Science is an example of a resolute transdisciplinary agenda (Cohen 1999; Gill \& Cohen 2009). It is focused on studying informing processes across various academic disciplines. The cornerstone is a model that includes the informer, client and delivery system. The informer and client roles can engage individuals (e.g., business analyst-manager, instructor-student, journalist-reader), groups (e.g., management team-shareholders) or entire institutions (e.g., academia-society). The delivery system can be different types of information systems. Informing Science has attracted an international community of scholars and generated a sizeable literature ${ }^{2}$. Even though Informing Science claims a transdisciplinary allegiance, the research appearing in its publishing outlets still does not match our conceptualisation of transdisciplinarity. Since the cornerstone model does not necessitate ontological and epistemological synthesis, this research is still interdisciplinary or multidisciplinary.

As part of conceptualising transdisciplinarity, IS scholars examined the issues of relevance and rigour. Generally, in IS research the relevance of research results for practice and methodological rigour have been deemed the

${ }^{2}$ See http://www.informingscience.org 
key criteria of the scholarly work quality (Desouza et al. 2006; Straub \& Ang 2011). Some scholars maintain that both rigour and relevance must also apply to IS-related transdisciplinary research (Teo \& Srivastava 2007). Others put more emphasis on relevance due to the orientation of transdisciplinarity on solving big practical problems (Hassan \& Will 2006). Moreover, Weber (2012) suggests that novelty and importance can be used for valuing transdisciplinary research projects. These ideas are consistent with the position of the transdisciplinarity proponents discussed in the previous section (Gibbons et al. 1994; Nicolescu 1994).

In conclusion, the IS field has inherently leaned beyond a disciplinary approach toward multidisciplinarity and interdisciplinarity. Transdisciplinarity has attracted scholars' attention but its outcomes are still programmatic and conceptual rather than empirical. However, the conceptualisations and research agendas indicate certain interest for transdisciplinarity. We appreciate this as a solid basis for making a transition toward transdisciplinarity.

\section{Transdisciplinary Research Opportunities}

IS research may benefit from interweaving its ICT focus with other disciplines at a transdisciplinarity level. In this section, we discuss topics that invite transdisciplinary research.

\section{Urban, Regional and Landscape Development}

Urban and or regional development faces a diversity of issues at global, regional and micro levels - these are interdependent and interwoven in complex relationships and systems. There is a need for meta-theoretical and integrated perspectives that enable the application of transdisciplinary approaches to urban development planning (Woiwode 2013). Transdisciplinary research agendas here include urban governance and communication; poverty, exclusion and social justice; climate change resilience; and the role of planning professionals and local politicians in urban management (Woiwode 2013). These topics pose crosscutting research questions for IS researchers. The topics compel that principles of software and systems design, ICT and design science coevolve with principles of planning in instituting effective urban development. 


\section{Health and Wellbeing}

Global health priorities are similarly complex and multidimensional. This fact opens up the possibility for transdisciplinary theory and practice, integrating methods and approaches from various disciplines to solve immediate health problems. Not merely a combination of expertise is needed, but a holistic unification of methods and disciplines; for example, contributing disciplines can be medical informatics, computer science, biostatics, psychology, social sciences and health economics (Ammenwerth et al. 2004). In this case, transdisciplinarity can lead researchers and practitioners to re-evaluate the multiple pathways to illness and wellbeing - informational, technical, sociocultural and environmental, among others (Pescosolido et al. 2008).

\section{Sustainability}

The practical, environmental application of digital technologies is a potential opportunity for a transdisciplinary approach involving IS research (Elliot 2011). Technology should try to not only minimise its own impact, but also serve in reducing the carbon footprint of other industries. Collaboration of different disciplines is necessary for approaching a common problem and creating solutions that can change business practices (Elliot 2011). Hovorka and Corbett's (2012) transdisciplinary framework responds to this research topic. The authors have highlighted innovation in terms of research approaches, the transdisciplinary conception of new knowledge and the integration of theory and practice facilitated by IS as essential foundations of maintaining a sustainable biosphere.

\section{Socially Responsive Policies}

Socially responsive policy study can be regarded as a method, process, program and practice of transdisciplinarity. Nguyen, Tapanainen and Obi (2014) proposed a topic connecting the concepts of ICT, tuition and gerontology. Specifically, elderly people often experience financial, physical and emotional impediments regarding their ICT proficiency. Even in developed countries like Germany, elderly people are inhibited to use eHealth systems because they have a perception that they do not have the necessary Internet skills to use these systems (Rockmann, Weeger \& Gewald 2015). In 
order to maximise the use of Internet-based health systems by elderly people, there is a need to improve their computer skills and Internet self-efficacy. ICT studies that incorporate social cognitive theory are able to gauge the level of Internet self-efficacy within this age group and the effect that prior computer and Internet usage has on these perceptions.

University-community programs of engagement are optimally suited for performing socially responsive policy projects. Universities are suitable for addressing immediate societal concerns since they can evaluate best practices and formal structures for community-engagement and ICT deployment for development purposes (Bailey, Burke, Weekes \& James 2014; Sen 1999; Tiwari \& Ibrahim 2012). In particular, social media can be used to integrate important aspects from various disciplines, such as psychology and ICT, in order to ensure successful community engagement projects in the tertiary environment (Tan, Stockdale \& Vasa 2011). The systems used in community engagement must not only be technically functional, but should also allow users to build social relationships, create a sense of belonging and facilitate a satisfactory experience.

\section{Information and Communication Technology for Development}

ICT4D is a movement of IS engagement that incorporates elements of transdisciplinary practice and scholarship. ICT4D has an important role in supporting the future of social and economic development with the integration of available technologies and knowledge (Nor \& Muhlberger 2011). This research can be regarded as both an academic field and a pragmatic effort in applying new technologies and systems for societal advancement. These goals are signified by the term 'pracademic' - a researcher that bridges the 'somewhat ethereal world of academia and the pragmatic world of practice' (Walker 2010:1). Compliant with the profile of a transdisciplinarian discussed above, the pracademic resembles a transdisciplinarity researcher focused on practical problems and the production of synthesis and innovation-based knowledge.

ICT4D is concerned with facilitating an inclusive modern society, where ICTs are catalysts for social and economic 'empowerment' and/or 'freedom' (Heeks 2008). This author posits that ICT4D can address the problem of digital exclusion, working to integrate communities into the digital era. Unwin (2009) deems support to rural developments the mission for 
ICT4D. Other authors concur that ICT4D can assist in achieving social, cultural and economic development (Harris \& Harris 2011; Sahay 2013). A number of authors agree that narrow economic development should not be the sole goal (Todaro 1991; Max-Neef, Elizalde \& Hopennayn 1991; Roode 2008). Instead, the goals are more diverse and apply to human-scale development. Examples of these are increased self-esteem and -autonomy and the emancipation from constraining material conditions and subjugation to other people and institutions (Roode 2008).

Twinomurinzi (2015) views a transdisciplinary approach as a way of harvesting, understanding and systematising views from industry and academia (both Computer Science and Information Systems) in order to stimulate the creation of software for mobile devices inherent to Africa. As part of a significant growth of the ICT4D literature a new research area has emerged called Mobile Phones for Development (Gomez 2013). Overall, ICT4D is shedding its a-theoretical past by exploring more conceptually nuanced and multidimensional foundations for its work. It yet needs to evolve toward transdisciplinarity in empirical research. Studies of ICT4D must thus look to explore and unpack the term's fundamental components, namely 'ICT' and '4D': what kinds of technologies are being deployed, for which users, and based on what expertise? Furthermore, what type of 'development' is foreseen and whose idea of 'development' is supported?

\section{Web Science}

Web science serves as a last example of an emerging field that calls for a transdisciplinary approach to study a complex phenomenon. Oinas-Kukkonen (2015) sees web science as an emerging discipline that can borrow many of IS's explanatory theories to move away from its current technical, computerscience dominated focus to include social and organisational aspects into its research visor. Web science should become a holistic science and a soulmate of IS. In fact, IS has the opportunity to be a central player in the transformation of web science.

Web science seeks more systematic and holistic thinking ... and IS can respond to this request. In a nutshell, the IS discipline provides approaches, methodologies, and tools for studying organizational, social, and end user issues in IT; particularly important is the emphasis 
on systems analysis and design and the use of IT in organizational and social settings (Oinas-Kukkonen 2015:41).

In summary, the literature points to six topical areas suitable to transdisciplinarity in which IS researchers can contribute: Urban/Regional and Landscape Development, Health and Wellbeing, Sustainability, Socially Responsive Policies, Information and Communication Technology for Development and Web Science. These topics are constructed with concern for practical significance and for achieving deep, multidimensional understanding of practical societal problems. These examples serve as grounds or support for the article's claim that Information Systems research can be elevated from a multi- and interdisciplinary field to a higher level of transdisciplinarity (see Figures 1-3). The presupposition that underlies the argument - an essential component of conceptual research (cf. Hirschheim 2008) - is that Information Systems scholars and practitioners aspire to find practical solutions based on sound theoretical foundations for complex software issues (cf. Oates 2006:2).

\section{Conclusion}

The preceding discussion reviewed the concepts of transdisciplinarity and its relevance for IS theory and practice. The article makes a contribution to the IS philosophy of science by clarifying the differences between various crossdisciplinary approaches, by synthesising various concepts about transdisciplinarity into a single, encompassing framework and by arguing that transdisciplinarity is a way to address wicked problems in the IS field.

A limitation of this article is that it does not explore the implications of the drive for transdisciplinarity for undergraduate and postgraduate teaching and learning in IS. While students tend to concentrate on the absorption of discipline-specific knowledge, employers also place a high premium on crossdisciplinary skills, i.e. the ability to innovate, to be flexible regarding job focuses and to adapt to changes in the computing industry (Lin-Stephens et al. 2017). Future work should, therefore, reflect on ways to nurture transdisciplinary competences in IS students. Another limitation of this article is that it assumes that individuals and organisations appropriate (adopt and adapt) technology, while it should be acknowledged that cultural values are also deeply embedded in technology and often lead to a situation of 'itocracy' (digital colonisation) (Phahlamohlaka \& Kroeze 2005). 
We explored essential properties of transdisciplinarity in conjunction with alternative approaches of disciplinarity, multidisciplinarity and interdisciplinarity. Existing frameworks focus on specific aspects of transdisciplinary research. Travica (2014) focuses on the integration of IS theory and organisational theory, Wahoff, Porto de Albuquerque and Rolf (2012) focus on information systems at the societal level, and Hovorka and Corbett (2012) focus on sustainability. The framework that is proposed in this article aims to synthesise various aspects into an encompassing and holistic framework. Transdisciplinarity deploys open ontology and epistemology and strives for knowledge synthesis, while attempting to resolve complex, emerging practical problems of a macro-societal significance. As such, it is superior to alternative cross-disciplinary approaches. It does not only require collaboration across disciplines, but also enriches individual disciplines. Transdisciplinarians, therefore, need a viewpoint of open-mindedness to facilitate holistic integration.

IS research is interdisciplinary and multidisciplinary in its foundations. However, it is still just aspiring to transdisciplinarity rather than demonstrating it in empirical research. Transdisciplinarity can be an avenue of improving prospects of the IS field that has been occupied with defining its own identity (Desouza et al. 2006; Hirschheim \& Klein 2012; Looney et al. 2014; Straub \& Ang 2011). The research rigour imperative (scrutinised and academically recognised research) would more likely be achieved through working with colleagues from other disciplines. Collaboration augments scrutiny, while prospects of recognition expand with transdisciplinary exposure and integration. The relevance imperative would also be achievable more easily because IS researchers would contribute to resolving complex social problems, such as those we have cited. Overall, transdisciplinary evolution of the IS field would enable the field to leap to a larger stage and expand its research clientele.

\section{Acknowledgements}

The University of South Africa (UNISA) is acknowledged for granting a period of research and development leave to the first author during which time the article was revised. The research was supported in part by UNISA and the National Research Foundation (NRF) of South Africa. Any opinion, finding or recommendation expressed in this material is that of the authors, and neither 
Jan Hendrik Kroeze, Bob Travica \& Izak van Zyl

the NRF nor UNISA accepts any liability in this regard. The authors would like to thank the editors and reviewers for their invaluable feedback that guided us to improve the article.

\section{References}

Alter, S. 2015. Overcoming Silo Thinking in the IS Discipline by Thinking Differently about IS and IT. Twenty-first Americas Conference on Information Systems Proceedings, pp. 1 - 13.

http://doi.org/10.1007/s00213-004-1788-8

Ammenwerth, E., J. Brender, P. Nykänen, H.U. Prokosch, M. Rigby \& J. Talmon 2004. Visions and Strategies to Improve Evaluation of Health Information Systems: Reflections and Lessons Based on the HIS-EVAL Workshop in Innsbruck. International Journal of Medical Informatics 73: 479 - 491. https://doi.org/10.1016/j.ijmedinf.2004.04.004

Ashby, W.R. 1991. Requisite Variety and its Implications for the Control of Complex Systems. In Klir, G.J. (ed.): Facets of Systems Science. Boston, MA: Springer. (International Federation for Systems Research International Series on Systems Science and Engineering, Volume 7: 405 - 417.) https://doi.org/10.1007/978-1-4899-0718-9 28

Augsburg, T. 2014. Becoming Transdisciplinary: The Emergence of the Transdisciplinary Individual. World Futures 70: 233 - 247.

https://doi.org/10.1080/02604027.2014.934639

Bailey, A., O. Burke, T. Weekes \& M. James 2014. University-community Engagement and the Role of ICT for Development Initiatives. SIG GlobDev 2014 Proceedings, Auckland, December 14, 2014, Paper 3. http://aisel.aisnet.org/globdev2014/3

Becker, J., J. vom Brocke, M. Heddier \& S. Seidel 2015. In Search of Information Systems (Grand) Challenges. Business \& Information Systems Engineering 57,6: 377 - 390.

https://doi.org/10.1007/s12599-015-0394-0

Bemgal, S. 2018. Technology Materiality and Individual Sensemaking. Twenty-fourth Americas Conference on Information Systems Proceedings. New Orleans, LA, pp. 1 - 9. Available at:

https://aisel.aisnet.org/amcis2018/AdvancesIS/Presentations/7/ (Accessed on 30 March 2019). 
Bernstein, J.H. 2015. Transdisciplinarity: A Review of its Origins, Development, and Current Issues. Journal of Research Practice 11: 1 - 20.

Buckingham, W., D. Burnham, C. Hill, P.J. King, J. Marenbon \& M. Weeks 2018. The Little Book of Philosophy. London: Dorling Kindersley.

Carayannis, E.G., D.F.J. Campbell \& S.S. Rehman 2016. Mode 3 Knowledge Production: Systems and Systems Theory, Clusters and Networks. Journal of Innovation and Entrepreneurship 5,17: 1 - 24.

https://doi.org/10.1186/s13731-016-0045-9

Castells, M. (ed.) 2012. Aftermath: The Cultures of the Economic Crisis. Oxford, UK: Oxford University Press.

Choi, B.C. \& A.W. Pak 2006. Multidisciplinarity, Interdisciplinarity and Transdisciplinarity in Health Research, Services, Education and Policy:

1. Definitions, Objectives, and Evidence of Effectiveness. Clinical and Investigative Medicine 29: 351 - 364.

Clark, B. \& C. Button 2011. Sustainability Transdisciplinary Education Model: Interface of Arts, Science, and Community (STEM). International Journal of Sustainability in Higher Education 12,1: 41 - 54. https://doi.org/10.1108/14676371111098294

Cohen, E. 1999. Reconceptualizing Information Systems as a Field of the Transdiscipline Informing Science: From Ugly Duckling to Swan. Journal of Computing and Information Technology 7: 213 - 219.

Davison, R.M. \& M.G. Martinsons 2016. Context is King! Considering Particularism in Research Design and Reporting. Journal of Information Technology 31: 241 - 249.

https://doi.org/10.1057/jit.2015.19

Demetis, D.S. \& A.S. Lee 2016. Crafting Theory to Satisfy the Requirements of Systems Science. Information and Organization, 26, 116 - 126. https://doi.org/10.1016/j.infoandorg.2016.09.002

Desouza, K.C., O.A. El Sawy, R.D. Galliers, C. Loebbecke \& R.T. Watson 2006. Beyond Rigor and Relevance towards Responsibility and Reverberation: Information Systems Research that Really Matters. Communications of the Association for Information Systems 17: 341 - 353.

https://doi.org/10.17705/1CAIS.01716

Diallo, S.Y. 2010. Towards a Formal Theory of Interoperability. PhD thesis, Old Dominion University. Ann Arbor, MI: ProQuest LLC (UMI Dissertation Publishing: UMI 3416870).

Drechsler, A. 2013. Design Science as Design of Social Systems - Implica- 
Jan Hendrik Kroeze, Bob Travica \& Izak van Zyl

tions for Information Systems Research. JITTA: Journal of Information Technology Theory and Application 14: 5 - 26.

Elliot, S. 2011. Transdisciplinary Perspectives on Environmental Sustainability: A Resource Base and Framework for IT-enabled Business Transformation. MIS Quarterly 35,1: 197 - 236.

https://doi.org/10.2307/23043495

Galliers, R.D. 2003. Change as Crisis or Growth? Toward a Trans-disciplinary View of Information Systems as a Field of Study: A Response to Benbasat and Zmud's Call for Returning to the IT Artifact. Journal of the Association for Information Systems 4,1: 337-351.

DOI: $10.17705 / 1$ jais. 00040

Ghani, R. 2018. Data Science for Social Good and Public Policy: Examples, Opportunities, and Challenges (Abstract). The 41 $1^{\text {st }}$ International ACM SIGIR Conference on Research \& Development in Information Retrieval Proceedings - SIGIR '18, July, 8-12, 2018, Ann Arbor, MI, 3.

https://doi.org/10.1145/3209978.3210231

Gibbons, M., C. Limoges, H. Nowotny, S. Schwartzman, P. Scott \& M. Trow 1994. The New Production of Knowledge: The Dynamics of Science and Research in Contemporary Societies. London, UK: Sage.

Gill, T.G. 2013. Complexity, Cybernetics, and Informing Science: Building a Better Mousetrap. Systemics, Cybernetics, and Informatics 11: 53 - 68.

Gill, T.G. \& E.B. Cohen (eds.). 2009. Foundations of Informing Science: 1999-2008. Santa Rosa, CA: Informing Science Press.

Gomez, R. 2013. The Changing Field of ICTD: Growth and Maturation of the Field, 2000 - 2010. The Electronic Journal of Information Systems in Developing Countries 58, 1-21.

https://doi.org/10.1002/j.1681-4835.2013.tb00408.x

Harris, C.A. \& R.W. Harris 2011. Information and Communication Technologies for Cultural Transmission among Indigenous Peoples. The Electronic Journal of Information Systems in Developing Countries 45,1: $1-19$.

https://doi.org/10.1002/j.1681-4835.2011.tb00318.x

Hassan, N.R. 2011. Is Information Systems a Discipline? Foucauldian and Toulminian Insights. European Journal of Information Systems 20,4: 456 $-476$.

https://doi.org/10.1057/ejis.2011.2

Hassan, N.R. \& H. Will 2006. Synthesizing Diversity and Pluralism in Infor- 
mation Systems: Forging a Unique Disciplinary Subject Matter for the Information Systems Field. Communications of the Association for Information Systems 17: 152 - 180.

https://doi.org/10.17705/1CAIS.01707

Heeks, R. 2008. ICT4D 2.0: The Next Phase of Applying ICT for International Development. Computer-IEEE Computer Society 41,6: 26 - 33. https://doi.org/10.1109/MC.2008.192

Hirschheim, R. 2008. Some Guidelines for the Critical Reviewing of Conceptual Papers. Journal of the Association for Information Systems 9,8: 432 - 441. https://doi.org/10.17705/1jais.00167

Hirschheim, R. \& H.K. Klein 2012. A Glorious and Not-so-short History of the Information Systems Field. Journal of the Association for Information Systems 13,4: 188 - 235.

https://doi.org/10.17705/1jais.00294

Holland, J.H. 2014. Complexity: A Very Short Introduction. Oxford, UK: Oxford University Press. https://doi.org/10.1093/actrade/9780199662548.001.0001

Hovorka, D.S. 2010. Moving beyond IS Identity: Concepts and Discourses. International Conference on Information Systems (ICIS) 2010 Proceedings, paper 174. Available at:

https://aisel.aisnet.org/icis2010_submissions/267

Hovorka, D.S. \& J. Corbett 2012. IS Sustainability Research: A Transdisciplinary Framework for a 'Grand Challenge'. 33 ${ }^{\text {rd }}$ International Conference on Information Systems (ICIS) 2012 Proceedings, Orlando, Florida, pp. 1 - 18. Available at:

https://aisel.aisnet.org/icis2012/proceedings/GreenIS/8/

Issa, H. \& B. Bahli 2018. Understanding the Consequences of Technostress: A Non-linear Perspective. ECIS 2018 Proceedings, pp. 1 - 23. Available at: https://aisel.aisnet.org/ecis2018 rp/71

Jackson, P. 2015. Networks in a Digital World: A Cybernetics Perspective. Twenty-Third European Conference on Information Systems (ECIS) Proceedings, Münster, Germany, 1-16.

http://doi.org/10.18151/7217364

Kant, I. 1977. Prolegomena to any Future Metaphysics that will be Able to Come Forward as Science: The Paul Carus Translation Extensively Revised by James W. Ellington. Indianapolis, IN: Hackett. 
Karppinen, P., T. Lehto, H. Oinas-Kukkonen, T. Pätiälä \& O. Saarelma 2014. Using Hermeneutics to Uncover Anomalies for Non-adoption of Behavior Change Support Systems. PACIS 2014 Proceedings. Taipei, July 9-12, Paper 110. Available at:

http://aisel.aisnet.org/pacis2014/110

Kirshbaum, D. 2002. Introduction to Complex Systems. Available at:

http://www.calresco.org/intro.htm

(Accessed on 24 December 2019.)

Klein, J.T. 2014. Discourses of Transdisciplinarity: Looking Back to the

Future. Futures 63: 68 - 74. (Accessed on 24 December 2019.)

https://doi.org/10.1016/j.futures.2014.08.008

Kothari, C. 2004. Research Methodology: Methods and Techniques. $2^{\text {nd }}$

Revised Edition. New Delhi: New Age.

Kroeze, I.J. 2005. Matrix Iuris: Travels in the Hyperreality of Law. SA Public

Law 20,2: 320 - 334. Available at:

https://journals.co.za/content/sapr/20/2/EJC97883

Kroeze, I.J. 2013. Legal Research Methodology and the Dream of Interdisciplinarity. Potchefstroom Electronic Law Journal 16,3: 36 - 65. https://doi.org/10.4314/pelj.v16i3.3

Kuhn, T.S. 1970. The Structure of Scientific Revolutions. Chicago: University of Chicago Press. (International Encyclopaedia of Unified Science, $2^{\text {nd }}$ Enlarged Edition, Volume II.)

Kyriakidou, A. \& W. Ventners 2007. The Multi-disciplinary Development of Collaborative Grids: The Social Shaping of a Grid for Healthcare. Proceedings of the 15th European Conference on Information Systems, ECIS Standing Committee, pp. 831 - 842. Available at:

https://aisel.aisnet.org/ecis2007/22/

Larsen, K.R., D. Hovorka, A. Dennis \& J. West 2019. Understanding the Elephant: The Discourse Approach to Boundary Identification and Corpus Construction for Theory Review Articles. Journal of the Association for Information Systems 20,7: 887 - 927.

DOI: $10.17705 / 1$ jais.00556. Available at:

https://aisel.aisnet.org/jais/vol20/iss7/15

Lawrence, R.J. 2010. Beyond Disciplinary Confinement to Imaginative Transdisciplinarity. In Brown, V.A., J.A. Harris \& J.Y. Russell (eds.): Tackling Wicked Problems through the Transdisciplinary Imagination. London: Earthscan. doi: https://doi.org/10.4324/9781849776530 
Leavy, P. 2011. Essentials of Transdisciplinary Research: Using Problemcentered Methodologies. Walnut Creek, CA: Left Coast.

Lin-Stephens, S., S. Smith, D. Richards, V. Pang, J. Uesi \& J. Athanasou 2017. Students and Employers Don't See Eye to Eye: The Case of Information Systems, Information Technology and Engineering. PACIS 2017 Proceedings. Available at:

https://aisel.aisnet.org/pacis2017/120.

Liu, F., E. Lim, C-W. Tan, \& W. Wang 2017. Uncovering the Boundaryspanning Role of Information Systems Research in Trans-disciplinary Knowledge Advancement. ICIS 2017 Proceedings, 21 pp. Available at: http://aisel.aisnet.org/icis2017/General/Presentations/17.

Lucas, C. 2000. Complexity and Artificial Life: What are They? Manchester: CALResCo Group.

Looney, C., D. Firth, H. Koch, D. Cecez-Kecmanovic, J.J.P. Hsieh, C. Soh, J. Valacich \& E.A. Whitley 2014. The Credibility Crisis in IS: A Global Stakeholder Perspective. Communications of the Association for Information Systems 34: 1175 - 1189. https://doi.org/10.17705/1CAIS.03461

MacInnis, D.J. 2011. A Framework for Conceptual Contributions in Marketing. Journal of Marketing 75, 4: 136 - 154. Available at: https://doi.org/10.2139/ssrn.1845968

MacInnis, D.J. 2016/2017. Developing Conceptual Articles for JCR: Research Curation. Journal of Consumer Research Winter. Available at: https://academic.oup.com/DocumentLibrary/JCR/Developing_Conceptu al_Articles_Research_Curations_JCR_MacInnis_Final.pdf

Madni, A.M. 2007. Transdisciplinarity: Reaching beyond Disciplines to Find Connections. Journal of Integrated Design \& Process Science 11: 1 - 11. Magee, B. 1999. Confessions of a Philosopher: A Personal Journey through Western Philosophy, from Plato to Popper. New York, NY: The Modern Library.

Markie, P. 2017. Rationalism vs. Empiricism. In The Stanford Encyclopaedia of Philosophy (Fall 2017). Available at:

https://plato.stanford.edu/archives/fall2017/entries/rationalismempiricism/

Max-Neef, M., A. Elizalde \& M. Hopennayn 1991. Human Scale Development: Conception, Application and Further Reflections. New York, NY: Apex Press. 
Jan Hendrik Kroeze, Bob Travica \& Izak van Zyl

Merriam Webster Online Dictionary. Discipline. 2016. Available at: http://www.merriam-webster.com/dictionary/discipline.

Mittelstrass, J. 2011. On Transdisciplinarity. Trames 15,4: 329 - 338. https://doi.org/10.3176/tr.2011.4.01

Mora, M., O. Gelman, D. Paradice \& F. Cervantes 2008. The Case for Conceptual Research in Information Systems. International Conference on Information Resources Management (CONF-IRM) Proceedings, 10 pp. Available at: http://aisel.aisnet.org/confirm2008/52

Morçöl, G. \& A. Wachhaus 2009. Network and Complexity Theories: A Comparison and Prospects for a Synthesis. Administrative Theory \& Praxis 31,1: 44 - 58. Available at:

https://doi.org/10.2753/ATP1084-1806310103

National Science Foundation 2019. Harnessing the Data Revolution (HDR):

Transdisciplinary Research in Principles of Data Science Phase I (NSF 19-550). Available at:

https://www.nsf.gov/pubs/2019/nsf19550/nsf19550.htm (Accessed 14 March 2019.)

Nguyen, T.T.H., T. Tapanainen \& T. Obi 2014. A Review of Information and

Communication Technology (ICT) Training for Elderly People - Toward Recommendations for Developing Countries. PACIS 2014 Proceedings, Chengdu, China, June 24-28, 2014, Paper 267. Available at: http://aisel.aisnet.org/pacis2014/267

Nguyen, H.T.T., T. Tapanainen, Y. Theng, S. Lundberg \& M. Luimula 2015. Fostering Communication between the Elderly and the Youth with Social Games. PACIS 2015 Proceedings, Singapore, July 5-9, 2015, Paper 227. Available at: http://aisel.aisnet.org/pacis2015/227

Nickerson, R.C., J. Muntermann \& U. Varshney 2010. Taxonomy Development in Information Systems: A Literature Survey and Problem Statement. AMCIS 2010 Proceedings 11 pp. Available at: http://aisel.aisnet.org/amcis2010/125

Nickerson, R.C., U. Varshney \& J. Muntermann 2013. A Method for Taxonomy Development and its Implication in Information Systems. European Journal of Information Systems 22: 336 - 359. https://doi.org/10.1057/ejis.2012.26

Nicolescu, B. 1994. The Charter of Transdisciplinarity. Available at: http://inters.org/Freitas-Morin-Nicolescu-Transdisciplinarity (Accessed on 2 April 2019). 
Nor, R.M. \& R. Muhlberger 2011. Community Exchange: Designing to Support Empathy and Interaction of Hope. World Journal of Social Sciences 1: 137 - 147.

Nowotny, H. 2004. The Potential of Transdisciplinarity. In Dunin-Woyseth, H. \& Nielsen, M. (eds.), Discussing Transdisciplinarity: Making Professions and the New Mode of Knowledge Production. Oslo: The Nordic Reader, Oslo School of Architecture.

Oates, B.J. 2006. Researching Information Systems and Computing. Los Angeles, CA: Sage.

Oinas-Kukkonen, H. 2015. Web Science: A Golden Opportunity for Applying Information Systems Theories. Journal of Information Technology Theory and Application (JITTA) 16,3: 37 - 58. Available at:

https://aisel.aisnet.org/jitta/vol16/iss3/3

Onik, M.F.A., E. Fielt \& G.G. Gable 2017. Towards a complex adaptive systems roadmap for Information Systems research. Twenty First Pacific Asia Conference on Information Systems Proceedings, Langkawi, 15 pp. Available at:

https://aisel.aisnet.org/pacis2017/106/

Onozuka, R., T. Yamazaki \& J. Kokuryo 2016. Redefiners of Discipline Borders: A Bayesian Detection Method for Conceptual Changes in Scientific Knowledge. ICIS 2016 Proceedings. Available at: https://aisel.aisnet.org/icis2016/DataScience/Presentations/1

Oxford Dictionaries Online 2016. Discipline. Available at:

http://www.oxforddictionaries.com/definition/english/discipline

Pescosolido, B.A., B.L. Perry, J.S. Long, J.K. Martin, J.I. Nurnberger (Jr.) \& V. Hesselbrock 2008. Under the Influence of Genetics: How Transdisciplinarity Leads us to Rethink Social Pathways to Illness. American Journal of Sociology 114: 171 - 201.

https://www.journals.uchicago.edu/doi/10.1086/592209

Phahlamohlaka, L.J. \& J.H. Kroeze 2005. Sacred Space in Cyber Space: An African perspective. Journal for Semitics 14,2: 413 - 440.

Piaget, J. 1972. The Epistemology of Interdisciplinary Relationships. In Apostel, L. et al. (eds.): Interdisciplinarity: Problems of Teaching and Research in Universities. (Centre for Educational Research and Innovation (CERI)). Paris, France: Organisation for Economic Cooperation and Development.

Popper, K. 1978. Three Worlds: The Tanner Lecture on Human Values, deli- 
Jan Hendrik Kroeze, Bob Travica \& Izak van Zyl

vered at the University of Michigan, April 7, 1978. Available at: https://tannerlectures.utah.edu/_documents/a-to-z/p/popper80.pdf

(Accessed on 21 March 2019).

Porto de Albuquerque, J. \& E.J. Simon 2007. Dealing with Socio-technical

Complexity: Towards a Transdisciplinary Approach to IS Research.

Proceedings of the 15th European Conference on Information Systems (ECIS 2007), 1458-1468.

Porto de Albuquerque, J., E.J. Simon, J. Wahoff \& A. Rolf 2009. The Challenge of Transdisciplinarity in Information Systems Research: Towards an Integrative Platform. In Cater-Steel, A. \& L. Al-Hakim (eds.): Information Systems Research Methods, Epistemology, and Applications. Hershey, PA: Information Science Reference (IGI Global).

DOI: https://doi.org/10.4018/978-1-60566-040-0.ch005

Raymond, E., S. Horsfall \& M.E. Lee (eds.). 1997. Chaos, Complexity and Sociology: Myths, Models, and Theories. Thousand Oaks, CA: Sage Publications.

Rivard, S. 2014. The Ions of Theory Construction. (Editor's Comments.) MIS Quarterly 38,2: iii - xiii. Available at:

https://aisel.aisnet.org/misq/vol38/iss2/2/

Rockmann, R., A. Weeger \& H. Gewald 2015. Elderly People in eHealth: Investigating Internet Self-efficacy and the Role of Occupational Internet Usage. AMCIS 2015 Proceedings, Puerto Rico, August 13-15. Available at: http://aisel.aisnet.org/amcis2015/SocTech/GeneralPresentations/21/

Rohlf, M. 2018. Immanuel Kant. In The Stanford Encyclopaedia of Philosophy (Summer 2018 ed.). Available at:

https://plato.stanford.edu/archives/sum2018/entries/kant/

Roode, D. 2008. ICT and Socio-economic Interventions at SEDIT. In Braun, M., H. Romijn \& D. Roode (eds.), Community-driven Projects: Reflections on a Success Story. Pretoria: Van Schaik Publishers.

Root, H. 2013. Dynamics among Nations: The Evolution of Legitimacy and Development in Modern States. Cambridge, MA: MIT Press. https://doi.org/10.7551/mitpress/9534.001.0001

Sahay, S. 2013. Are we Building a Better World with ICTs? Empirically Examining this Question in the Domain of Public Health in Developing Countries. Proceedings of the $12^{\text {th }}$ International Conference on Social Implications of Computers in Developing Countries, Ocho Rios, Jamaica, May 2013, pp. 18-20. 
Sen, A. 1999. Development as Freedom. Oxford: Oxford University Press.

Straub, D. \& S. Ang 2011. Editor's Comments. Rigor and Relevance in IS Research: Redefining the Debate and a Call for Future Research. MIS Quarterly 35: iii - xi.

https://doi.org/10.2307/23043485

Tan, F.T.C., R. Stockdale \& R. Vasa 2011. Leveraging Emerging Web Technologies for Community Engagement Project Success in Higher Education. ECIS 2011 Proceedings, Helsinki, June 9-11, Paper 207. Available at:

http://aisel.aisnet.org/ecis2011/207

Teece, D. 2007. Explicating Dynamic Capabilities: The Nature and Microfoundations of (Sustainable) Enterprise Performance. Strategic Management Journal 28: 1319 - 1350. https://doi.org/10.1002/smj.640

Teece, D., G. Pisano \& A. Shuen 1997. Dynamic Capabilities and Strategic Management. Strategic Management Journal 18,7: 509 - 533. https://doi.org/10.1002/(SICI)1097-0266(199708)18:7<509::AID-

SMJ882>3.0.CO;2-Z

Teo, T.S.H. \& S.C. Srivastava 2007. Information Systems (IS) Discipline Identity: A Review and Framework. Communications of the Association for Information Systems 20: 518 - 544.

https://doi.org/10.17705/1CAIS.02033

Tiwari, M. \& S. Ibrahim 2012. Sustainable Human Development at the Grass Roots: Different Contexts, Similar Ingredients? Oxford Development Studies 40,1: 69 - 85.

https://doi.org/10.1080/13600818.2011.650161

Todaro, M.P. 1991. Economic Development in the Third World. $4^{\text {th }}$ Edition. New York, NY: Longman.

Tolk, A., S.Y. Diallo, J.J. Padilla \& C.D. Turnitsa 2013. How is M\&S Interoperability Different from other Interoperability Domains? $M \& S$ Journal Winter 2012 - 2013: 5 - 14.

Twinomurinzi, H. 2015. Expert Views on Stimulating Mobile Apps in Africa as a Creative Industry. Conf-IRM 2015 Proceedings, Ottawa, Ontario, Canada, May 18-20, 2015, Paper 11. Available at: http://aisel.aisnet.org/confirm2015/11

Travica, B. 2014. Examining the Informing View of Organization: Applying Theoretical and Managerial Approaches. Hershey, PA: IGI Global. https://doi.org/10.4018/978-1-4666-5986-5 
Travica, B. 2015. 4 Worlds: Coping with Technology Complexity. Proceedings of the Americas Conference on Information Systems, Puerto Rico, August 13-15, 2015. Available at:

https://aisel.aisnet.org/amcis2015/ISPhil/GeneralPresentations/1/

Unwin, T. 2009. ICT4D: Information and Communication Technology for Development. Cambridge: Cambridge University Press.

Wahoff, J.H., J. Porto de Albuquerque \& A. Rolf 2012. The Mikropolis Model: A Framework for Transdisciplinary Research of Information Systems in Society. In Dwivedi, Y.K., Wade, M.R. \& Schneberger, S.L. (eds.): Information Systems Theory: Explaining and Predicting Our Digital Society. Volume 2. London: Springer, 367-386.

https://doi.org/10.1007/978-1-4419-9707-4_18

Walker, D.T. 2010. Being a Pracademic - Combining Reflective Practice with Scholarship: Keynote address. AIPM Conference, Darwin, 10-13 October 2010.

Weber, R. 2012. Evaluating and Developing Theories in the Information Systems Discipline. Journal of the Association for Information Systems 13,1: 1 - 30 .

https://doi.org/10.17705/1jais.00284

Webster, J. \& R.T. Watson 2002. Analyzing the Past to Prepare for the Future: Writing a Literature Review. MIS Quarterly 26,2: xiii - xxiii. Available at: www.jstor.org/stable/4132319

Weick, K. 1990. Technology as Equivoque: Sensemaking in New Technologies. In Goodman, P. (ed.): Technology and Organizations. San Francisco, CA: Jossey-Bass.

Woiwode, C. 2013. New Departures in Tackling Urban Climate Change:

Transdisciplinarity for Social Transformation: A Critical Appraisal of the WBGU's 2011 Report. Integral Review: A Transdisciplinary \& Transcultural Journal for New Thought, Research, \& Praxis 9,2: 384 411.

Yadav, M.S. 2010. The Decline of Conceptual Articles and Implications for Knowledge Development. Journal of Marketing 74,1: 1 - 19.

https://doi.org/10.1509/jmkg.74.1.1

Zmud, R.W. 1998. Editor's Comments. MIS Ouarterly 22,2,June: xxix - xxxii. Available at:

https://misq.org/skin/frontend/default/misq/pdf/TheoryReview/EdComm entsV22I2.pdf 
Information Systems in a Transdisciplinary Perspective

Jan Hendrik Kroeze

School of Computing University of South Africa

Science Campus

Roodepoort

kroezjh@unisa.ac.za

Bob Travica

University of Manitoba

Canada

University of South Africa (Visiting Researcher)

Science Campus

Roodepoort

Bob.Travica@umanitoba.ca

Izak van Zyl

Faculty of Informatics and Design

Cape Peninsula University of Technology

Cape Town

VanZylIz@cput.ac.za 